\title{
Asia Africa Development Divergence: A Question of Intent
}

\section{GDE DWITYA ARIEF METERA}

Northwestern University

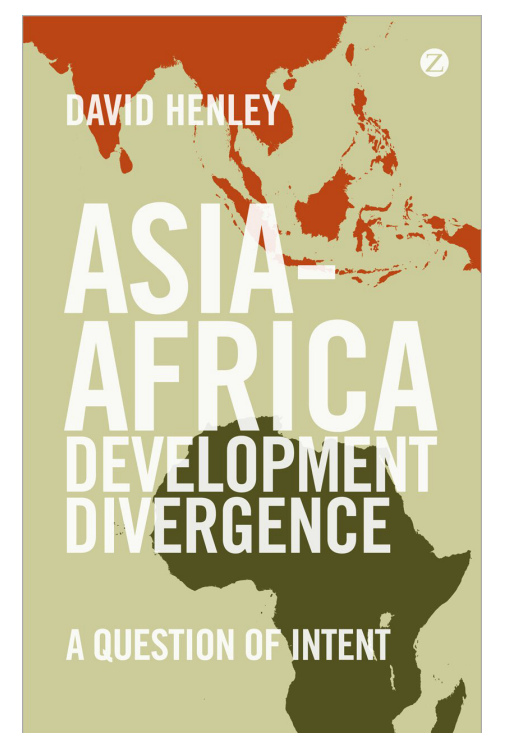

Title:

Asia Africa Development Divergence:

A Question of Intent

Author:

David Henley

Publisher:

Zed Books Ltd (2015)

Pages:

264

ISBN:

978-1-78360-278-0

\begin{abstract}
A perennial question at the heart of economic history is one of explaining the gap in the level of prosperity between countries that the economic historian Angus Maddison refers to as on the one hand, "developed"-comprises of Western Europe, its offshoots as well as Japan-and on the other hand, "developing"-comprises of most notably Africa, but also much of Asia and Latin America. While this variation in the level of prosperity is understood as originated in the $19^{\text {th }}$ century and continues to be an important research subject, a recent $20^{\text {th }}$ century development provides yet another important research puzzle. At least as early as the 1980s some developing countries attained a level of development comparable to those of the developed ones while many others stuck behind in their state of underdevelopment. The current book under review by David Henley, an Indonesianist based at Leiden University, aims squarely to tackle the latter puzzle of diverging developmental trajectories in those developing global South. Bringing evidence from comparisons of cases across Southeast Asia and Africa, the book braves the dense jungle of research on the political economy of development as it seeks to bring into the table a "rigorously comparative study of the development histories" (p. 52).
\end{abstract}


The book argues that a set of factors explains the diverging trajectories of development in 6 countries under scrutiny: the successful trajectories of Indonesia, Malaysia, and Vietnam, and the stunted trajectories of Nigeria, Kenya, and Tanzania. This set of factors includes (i) sound macroeconomic policies tackling inflation that lead to macroeconomic stability (ii) economic freedom to peasants, and (iii) pro-poor public spending. All of them should be present as each factor is individually necessary but not sufficient to effect successful development (p.12-14). Altogether, the presence of these policies in his Southeast Asian cases amount to a state-led agricultural development that later serves as a foundation for export-industrialization. Similarly, the absence of these policies in his African cases leads to no less than a developmental failure as exemplified Nigeria, Tanzania, and Kenya. Ultimately, the book argues, the presence and absence of such policies can be accounted for by the intention underlying policymaking on the part of the political elites of those countries.

Henley develops his argument through seven chapters of the book. The first two chapters set the research question, a brief sketch of his theory, as well as a minimal literature review. Chapter 3 discusses the first two preconditions that Henley identifies namely sound macroeconomic policies and economic freedom to the peasants. The fourth chapter follows with a discussion on the centrality of the policies on the rural-agricultural sector in the process leading to successful later export industrialization focusing on the comparison between Indonesia and Nigeria. Chapter 5 extend the discussion to the cases of Malaysia, Thailand, Tanzania, and Kenya. Chapter 6 points to the underlying principles animating policy adoptions in Southeast Asia and Africa respectively. And finally, chapter 7 concludes by exploring the reasons behind different intentions of policymakers in Indonesia and Nigeria.

While the book formally juxtaposes three pairs of cases, at the heart of its comparison and where the meat of the analytical narratives can be found throughout the book are the cases of Indonesia and Nigeria. The book reiterates the familiar story that the agricultural sector shoulders the early phase of growth in Indonesia. Food crop agriculture production, most notably rice, rises to an unprecedented degree. Areal yields of rice rise to 80\% from 1968 to 1985 . Consequently, within only a decade from 1974 to 1984 Indonesia transforms itself from being the largest rice importer in the world into self-sufficiency. The government is mainly responsible for this success by providing farmers with high-yielding varieties of rice, subsidizing fertilizers, and improving irrigation systems. During the 1970s and 1980s, the most substantial chunk of the Indonesian government budget goes to the agricultural sector. This expenditure is thirty times higher than those during the late colonial period (p. 90-92). Focus on the development of the rural-agricultural sector and the success afterward has critical ramification. 
Increased production of food induces general stability of food prices which later stabilizes wages. Progress in agricultural development thus provides stimulants for the rise of export manufacturing industries that depend primarily on low wages of labor. This scenario is indeed within the purview of the first five-year development plan (Pelita I) in 1969 as the Indonesian economist Widjojo Nitisastro writes (p. 103-104). This strong commitment toward the development of the rural-agricultural sector, or the rural bias as the book argues, is mostly found wanting in the case of Nigeria and other African countries.

The book presents its argument in a clear and readable fashion, much to the delight of its readers. This strength aside, perhaps the only aspect that could be improved from the book, if any, is a clear sense of intended audience. Advanced readers in social science would naturally demand a more rigorous methodological innovation in establishing causality. As a case in point, the book could arguably do a better job at excluding other explanatory variables that confound and interact with macroeconomic policies in the causal processes leading toward growth. For instance, international aid and oil bonanza that enable development spending in the first place are clearly at play as the story of Indonesia, Nigeria, and other cases unfold in the book. A logical question from a reader is thus: if alternative causes other than the ones the book identifies is clearly at play, why are they excluded? And which variables are more important in explaining growth? Statistical analysis could quantify the effect size of each variables and probe for interaction terms between them, but comparative historical research design could not. What a comparative historian usually do is to acknowledge the effect of such variables and to get back to the drawing table reexamining the combination of factors that yields our outcome of interest.

Similarly, for specialists in Indonesian economic history, an original finding beyond the centrality of the rural-agricultural sector in explaining Indonesia's growth miracle-suggested as early as perhaps the publication of Anne Booth's Agricultural Development in Indonesia-would be a more exciting read. The dominant use of secondary literature, while prevalent in the works of comparative history, also possibly gets on the nerves of historians. Not to mention the simplification of complexities regarding each country policymaking history, most notably the absence of politics, makes the book appear less enticing in the eyes of history buffs. The old adage of "men making history, but not as they pleased; they make it under circumstances existing already, given and transmitted from the past" runs against every fiber of the book that places a premium on a voluntaristic view of the world. Is it really the case that "policymakers at the apex of the national political system have not seriously tried to make it happen"? (p. 177).

While this non-specificity of an intended audience might be to some a 
flaw of the book, it could also be its supreme virtue. The book is consequently much more readable to the general audience and non-specialists not concerned either by technicalities of methods marring the social science or the details of the economic history of each of the book's country cases. More importantly, the book is remarkable in its attempt to be both comparative and theoretical at the same time which is not typical of the works by a country specialist. For this daring comparative endeavor, cheers and salute to the book. 